\title{
CRUSTACEA DECAPODA DA PRAIA ROCHOSA DA ILHA DO FAROL, MATINHOS, PARANÁ. II. DISTRIBUIÇÃO ESPACIAL DE DENSIDADE DAS POPULAÇÕES ${ }^{1}$
}

\author{
Setuko Masunari ${ }^{2}$ \\ Janete Dubiaski-Silva ${ }^{3}$
}

\begin{abstract}
Decapod CRUSTACEANS From rocky SHore at Farol Isle, Matinhos, ParanÁ, Brazil. II. Spatial distribution of population densities. A study of the spatial distribution of the decapod populations from a rocky shore at Farol Isle, Matinhos, State of Paraná, Brazil ( $25^{\circ} 51^{\prime} \mathrm{S}, 48^{\circ} 32^{\prime} \mathrm{W}$ ) was carried out. In the supralittoral the rocky surface is covered partially by a layer of litter coming from the terrestrial habitats; in the midlittoral boulders and pebbles cover the rocky basin and in the infralittoral, there is a belt of seaweeds. A total of 8 samples were taken by hand, two from each of the following levels: supralittoral (emersion time 8-12 hours), upper midlittoral (4-8), lower midlittoral (0-4) and limit between midlittoral and infralittoral, monthly, from May/1990 to April/1991. The number of species increased from supralittoral (5) to infralittoral (22) and a clear vertical zonation on density was observed according to the emersion time gradient. The supralittoral is characterized by grapsids Armases angustipes (Dana, (1852), Cyclograpsus integer H. Milne Edwards, 1837 and Metasesarma rubripes (Rathbun, 1897) which have terrestrial habits and aerial respiration as a main way in obtaining the oxygen. In the midlittoral, the decapods show three basic types of adaptation against emersion desiccation and thermal stresses: (1) by digging into wet mud among the stones such as Panopeus americanus Saussure, 1857, Panopeus occidentalis Saussure, 1857 and Eurypanopeus abbreviatus Stimpson, 1860, (2) by resting in shady and wet space between the boulders and pebbles or underside of them, like Pachygrapsus transversus (Gibbes, 1850), Petrolisthes armatus (Gibbes, 1850) and adults of Menippe nodifrons Stimpson, 1859 and (3) by clinging over the soaked filamentous algae layer on the pebbles or bouders surfaces, a strategy observed in small species such as Pilumnus dasypodus Kingsley, 1879, Podochela sp., Petrolisthes galathinus (Bosc, 1801), Alpheus bouvieri A. Milne Edwards, 1878 and juveniles of Menippe nodifrons. In the infralittoral, small species which are vulnerable to desiccation stresses share space by diversification of their diet and adaptation strategies such as camouflage, body color change according to the substratum, flattened body for tight adhesion on hard surface and rapid movements. The main species of this zone are Petrolisthes armatus, Petrolisthes galathinus, juveniles of Menippe nodifrons, Epialtus brasiliensis Dana, 1852, P. dasypodus, Synalpheus fritzmuelleri Coutière, 1909, Megalobrachium roseum (Rathbun, 1900) and species of Palaemonidae. The rocky shore at Farol Isle is a complex architectural
\end{abstract}

1) Contribuição número 929 do Departamento de Zoologia, Universidade Federal do Paraná.

2) Departamento de Zoologia, Universidade Federal do Paraná. Caixa Postal 19020, 81531-990 Curitiba, Paraná, Brasil.

E-mail: setmas@bio.ufpr.br

3) Doutoranda do Curso de Pós-graduação em Ciências Biológicas, área de Zoologia. Bolsista do CNPq. 
environment due to the conjunction of diversified habitats such as litter over a hard surface, spaces and crevices among boulders and pebbles, muddy substratum and phytal.

KEY WORDS. Decapod crustacean, spatial density distribution, zonation, rocky shore, Farol Isle

A seqüência espacial de organismos sésseis no sentido vertical ou zonação em costões rochosos do litoral marinho é universal, envolvendo na maioria das vezes o mesmo grupo de seres vivos em qualquer parte do mundo, dos trópicos aos pólos. O litoral constitui uma transição entre os ambientes marinho e terrestre, mas, devido ao movimento de água associado às marés, ondas e borrifos, a transição é gradual, criando um habitat no qual nenhum organismo totalmente marinho ou totalmente terrestre possa se desenvolver plenamente. Teoricamente, qualquer área de gradiente de transição entre dois ambientes distintos poderia ser colonizada igualmente por organismos de ambas as fontes; contudo, em habitats entremarés de costão rochoso, a grande maioria dos organismos é de origem marinha. Somente na zona acima do nível máximo das marés de sizígia, onde há efeitos das batidas das ondas e dos borrifos, os organismos são predominantemente de origem terrestre (BARNES \& HUGHES 1988).

A emersão é estressante para os organismos marinhos, assim como a imersão o é para os terrestres. A inundação alternada e a exposição ao ar são os fatores ambientais mais importantes na determinação dos tipos de organismos que vivem em zonas entremarés, e são as razões porque os organismos sésseis da zona entremarés de costões rochosos são semelhantes em qualquer litoral, apesar das marcantes dissimilaridades no clima (BARNES \& HUGHES 1988).

A zonação de costões rochosos pode ser estabelecida através de assentamento seletivo ou sobrevivência seletiva de larvas das espécies sésseis. Constituem desvantagens para organismos sésseis que vivem nas faixas altas da zona entremarés, o estresse térmico e a dessecação, o acesso reduzido a oxigênio dissolvido e 0 tempo limitado de alimentação (LEVINTON 1982). Há uma tendência geral em considerar que o limite superior de distribuição das espécies sésseis está relacionado com as perturbações físicas do ambiente como estresse térmico e dessecação, enquanto os limites inferiores são, frequentemente, o resultado de interações bióticas, tais como competição e predação (CONNELL 1961; PETRAITIS 1987).

A zonação de organismos sésseis foi estudada por pesquisadores estrangeiros (cf. revisão em GRIFFITHS \& BRANCH 1991 e em LIVELY et al. 1993 para interações biológicas) e brasileiros ( $c f$. PAULA 1987 e VILLAÇA 1990 para revisão).

A zonação de animais vágeis em costões rochosos é menos evidente (BARNES \& HUGHES 1988), os quais mostram adaptações para manter-se numa certa posição vertical ao longo do costão rochoso (LEVINTON 1982). A zonação de Crustacea Decapoda na região entremarés foi estudada em ambientes variados como marismas, praias rochosas, bancos de ostras, praias arenosas, manguezais e baixios estuarinos. CALADO \& LACERDA (1993) caracterizaram verticalmente os costões rochosos e substratos não consolidados de praias exposta e abrigada, no que se refere à distribuição dos Decapoda e Isopoda, no litoral do Estado de Pernambuco. $\mathrm{Na}$ 
praia abrigada, o supralitoral foi caracterizado pela presença de Armases angustipes (Grapsidae), o mediolitoral por espécies de Xanthidae, Alpheidae, Porcellanidae, Diogenidae, Ocypodidae e por Pachygrapsus transversus e Armases angustipes (ambos Grapsidae) e, finalmente, o infralitoral por espécies de Majidae e Palaemonidae.

Espécies vágeis que vivem acima da linha da maré média (MTL) são usualmente mais resistentes à dessecação do que aquelas formas encontradas principalmente ou exclusivamente abaixo da referida linha. Espécies residentes na parte mais interna de fissuras são menos resistentes à dessecação do que aquelas encontradas na porção mais externa das mesmas (KENSLER 1967).

As características físicas de cada faixa entremarés constituem os fatores primordiais da zonação dos Crustacea Decapoda. Destas, as mais importantes são o gradiente do grau de dessecação (KENSLER 1967; PELLEGRINO 1984; JENSEN \& ARMSTRONG 1991), do teor de salinidade (TEAL 1958; SHUMWAY 1983; HANEKON \& ERASMUS 1988), do tipo de substrato (TEAL 1958; ICELY \& JONES 1978), da microtopografia e da cobertura vegetal (DWORSCHAK 1987) e da combinação de vários fatores (GRIFFIN 1971).

O presente trabalho visa descrever a distribuição de densidade das espécies de Decapoda da praia rochosa da Ilha do Farol, Matinhos, Paraná, na tentativa de reconhecer alguma zonação em função do gradiente de tempo de emersão na zona litorânea.

\section{MATERIAL E MÉTODOS}

O mapa e a descrição detalhada do local de pesquisa bem como a metodologia de coleta encontram-se em MASUNARI et al. (1998).

A praia rochosa do presente estudo localiza-se na face oeste da Ilha do Farol e, no limite superior da mesma encontra-se uma mata secundária, onde crescem, também, árvores típicas de maguezais como Laguncularia racemosa Gaertn (Combretaceae) e Avicennia schaueriana Stapf \& Leechmann (Avicenniaceae). Entretanto, estas são representadas por arbustos de pequeno porte, não se observando qualquer exuberância comparável a manguezais do estado.

No supralitoral, o substrato rochoso é coberto parcialmente por serapilheira oriunda da mata secundária que, juntamente com pedregulhos constitui um esconderijo para espécies semi-terrestres de Decapoda. Na zona mediolitorânea e infralitorânea superior, a presença de matacões e cascalhos entremeados com areia faz deste ambiente um local particularmente abundante em Decapoda. No limite entre o mediolitoral e o infralitoral superior há um cinturão de algas macroscópicas pardas e vermelhas; abaixo destas, há uma faixa de areia.

Ao longo da transecção (MASUNARI et al. 1998) foram estabelecidas quatro faixas de amostragem entre a mata secundária e o infralitoral superior, num gradiente de tempo de emersão. As faixas foram denominadas de nível 1, 2, 3 e 4 correspondentes, respectivamente, à faixa do supralitoral, mediolitoral superior, mediolitoral inferior e ao limite entre o mediolitoral e o infralitoral. A última faixa, referente ao limite entre o mediolitoral e infralitoral, foi denominada no presente trabalho como infralitoral. 
No litoral do Estado do Paraná, a maré é do tipo semi-diurno; segundo DHN $(1990,1991)$, o nível médio da maré é de $0,84 \mathrm{~m}$ na Barra do Porto de Paranaguá Canal da Galheta $\left(25^{\circ} 34^{\prime} 04^{\prime \prime S}\right.$ e $\left.48^{\circ} 19^{\prime} 00^{\prime \prime} \mathrm{W}\right)$, o ponto de medida de altura da maré mais próximo do local de coleta. Durante o período de coleta, a altura mínima da maré prevista nos dias de coleta foi de $0,0 \mathrm{~m}$ em todos os meses de coleta com exceção de dezembro/1990 (0,1m); em novembro/1990 (0,2m) não houve coleta de material biológico devido a uma forte tempestade. Em contraste, a altura máxima da maré prevista nos dias de coleta mostrou uma variação de $0,5 \mathrm{~m}(1,2 \mathrm{~m}$ em março/1991 e 1,7m em dezembro/1990 e janeiro/1991). Portanto, nos dias de coleta, durante as marés vazantes, o nível 1 ficou emerso cerca de 8-12 horas, o nível 2 de 4-8 horas, o nível 3 de $0-4$ horas e o nível 4, sempre submerso.

As coletas foram realizadas mensalmente, de maio de 1990 a abril de 1991 , durante as marés vazantes de sizígia. Foram obtidas manualmente duas amostras do material biológico de cada nível acima descrito, totalizando oito mensais e 88 durante o período de estudo. A temperatura do ar variou de $13,0^{\circ} \mathrm{C}$ (maio) a $27,0^{\circ} \mathrm{C}$ (março), a da água de superfície de $16,0^{\circ} \mathrm{C}$ (julho) a $28,0^{\circ} \mathrm{C}$ (fevereiro) e a salinidade da água de superfície de $6,7 \%$ (novembro) a $29,4 \%$ (junho) ( $c f$. gráficos de flutuação em OLIVEIRA \& MASUNARI 1995).

$\mathrm{Na}$ figura 1 , as densidades relativas significativamente maiores, segundo o teste de Freedman (linha espessa), foram discriminadas das menores (linha fina) para $\mathrm{p}<0,05$. Para a elaboração da figura 2 , os valores de comprimento da carapaça dos animais foram extraídos da literatura a seguir, considerando sempre o maior valor citado para cada espécie: RATHBUN $(1925,1930)$, WASS (1955), CHACE \& HobBS (1969), CHRISTOFFERSEN (1979), WilliAMS (1984), ABELE \& KIM (1989), Silva et al. (1989), ABELE (1992) e BosCHI et al. (1992). Exceção foi feita a Panopeus americanus, Menippe nodifrons, Petrolisthes armatus e Podochela sp. que tiveram o referido parâmetro medido nos exemplares do presente trabalho. Para os Alpheoidea, foi considerado como comprimento da carapaça a soma do comprimento do rostro e do cefalotórax.

\section{RESULTADOS}

A tabela I apresenta a amplitude de variação dos valores de densidade em cada nível, o comprimento máximo da carapaça e a freqüência mensal de ocorrência das espécies registradas durante o período de estudo. A discriminação dos meses de ocorrência de cada espécie encontra-se em MASUNARI et al. (1998).

As diversas espécies de Decapoda do presente estudo, especialmente as mais abundantes e frequentes, mostraram uma distribuição zonada nítida ao longo do gradiente do tempo de emersão. Todos os Grapsidae, Xanthidae, os Alpheoidea Alpheus bouvieri e Synalpheus fritzmuelleri, os Porcellanidae Petrolisthes armatus e Petrolisthes galathinus e os Majidae Epialtus brasiliensis, num total de 14 espécies, ocorreram com freqüência mensal de, pelo menos, seis vezes em um dos quatro níveis analisados. $O$ restante ( 13 espécies) ocorreu com freqüência menor do que este valor, e está representado por Paguridae, Palaemonidae, pela maioria dos Majidae, Alpheoidea e metade dos Porcellanidae (Tab. I). 
Tabela I. Ilha do Farol, Paraná. Amplitude de oscilação da densidade $\left(\mathrm{n}^{\circ}\right.$ ind. $\left.\mathrm{m}^{-3}\right)$, comprimento da carapaça e número de meses de ocorrência $(\mathrm{N})$ das espécies de Decapoda registradas nos quatro niveis durante o período estudado.

\begin{tabular}{|c|c|c|c|c|c|c|c|c|c|}
\hline \multirow[t]{2}{*}{ Espécies } & \multirow{2}{*}{$\begin{array}{c}\text { Comprimento } \\
\text { da carapaça } \\
\text { (mm) }\end{array}$} & \multicolumn{2}{|l|}{ Nivel 1} & \multicolumn{2}{|l|}{ Nivel 2} & \multicolumn{2}{|l|}{ Nivel 3} & \multicolumn{2}{|l|}{ Nivel 4} \\
\hline & & $n^{\circ}$ ind. $m^{-3}$ & $N$ & $\mathrm{n}^{\circ}$ ind. $\mathrm{m}^{-3}$ & $\mathrm{~N}$ & $n^{\circ}$ ind. $m^{-3}$ & $N$ & $n^{\circ}$ ind. $m^{-3}$ & $\mathrm{~N}$ \\
\hline Armases angustipes & 22,5 & $7,51-1050,00$ & 11 & & & & & & \\
\hline Metasesarma rubripes & 17,0 & $2,27-16,67$ & 7 & & & & & & \\
\hline Cyclograpsus integer & 13,0 & $2,38-20,00$ & 7 & 1,96 & 1 & & & & \\
\hline Pachygrapsus transversus & 21,7 & 4,17 & 1 & $10,81-76,47$ & 11 & $19,23-105,56$ & 11 & $5,13-29,79$ & 9 \\
\hline Eurypanopeus abbreviatus & 15,8 & & & $1,09-23,53$ & 11 & $0,64-70,51$ & 10 & $0,37-4,44$ & 5 \\
\hline Panopeus americanus & 21,1 & & & $2,74-44,12$ & 10 & $2,68-50,79$ & 11 & $1,08-4,26$ & 2 \\
\hline Panopeus occidentalis & 27,7 & & & $1,25-21,57$ & 11 & $0,64-22,22$ & 10 & $0,76-4,26$ & 5 \\
\hline Menippe nodifrons & 40,5 & & & $1,09-2,78$ & 2 & $1,28-11,48$ & 8 & $3,79-70,00$ & 11 \\
\hline Pilumnus dasypodus & 11,0 & & & $2,70-6,57$ & 2 & $2,13-21,79$ & 8 & $4,55-257,45$ & 11 \\
\hline Clibanarius tricolor & - & & & & & 2,78 & 1 & & \\
\hline Alpheus bouvieri & 10,0 & 1,14 & 1 & $2,05-8,33$ & 4 & $0,64-12,77$ & 6 & $0,37-2,13$ & 3 \\
\hline Synalpheus fritzmuelleri & 7,5 & & & 0,68 & 1 & & & $1,48-50,93$ & 10 \\
\hline Synalpheus brevicarpus & - & & & & & & & $0,58-2,04$ & 4 \\
\hline Alpheus formosus & - & & & & & 1,14 & 1 & $0,37-0,58$ & 2 \\
\hline Alpheus cf. floridanus & - & & & & & $1,14-1,28$ & 2 & & \\
\hline Synalpheus minus & - & & & & & & & 4,30 & 1 \\
\hline Petrolisthes armatus & 13,5 & & & $8,13-411,11$ & 11 & $111,76-668,25$ & 11 & $26,85-492,00$ & 11 \\
\hline Petrolisthes galathinus & 17,0 & & & & & 3,51 & 1 & $1,17-31,63$ & 9 \\
\hline Megalobrachium roseum & 6,5 & & & & & & & $1,85-9,18$ & 5 \\
\hline Pochycheles monifer & - & & & & & & & 0,93 & 1 \\
\hline Podochela sp. & 4,6 & & & & & 0,89 & 1 & $0,74-6,38$ & 4 \\
\hline Epialtus brasiliensis & 13,7 & & & & & & & $0,74-12,24$ & 6 \\
\hline Microphrys bicomutus & - & & & & & & & $0,74-4,48$ & 3 \\
\hline Apiomithrax violaceus & - & & & & & & & $2,78-3,23$ & 2 \\
\hline Pelia rotunda & - & & & & & & & $1,02-1,49$ & 2 \\
\hline Palaemonetes sp. & - & & & & & & & $2,00-4,26$ & 2 \\
\hline Periclemenes americanus & - & & & & & & & $0,74-3,06$ & 2 \\
\hline
\end{tabular}

Grapsidae (Tab. I). Apenas Pachygrapsus transversus ocorreu nos quatro níveis, com densidade máxima $\left(105,56\right.$ ind. $\left.\mathrm{m}^{-3}\right)$ no nível 3 e mínima no $1(4,17$ ind. $\mathrm{m}^{-3}$ ); entretanto, nos níveis 2 e 3 , a espécie mostrou densidades significativamente superiores (Fig. 1). No nível 1, esta espécie foi registrada apenas uma vez (de um total de onze amostragens), em contraste com os demais onde ela ocorreu em todos os meses amostrados (níveis 2 e 3 ) ou nove vezes (nível 4). Quase sempre ela foi observada na superfície superior ou inferior das rochas sem mostrar comportamento de se enterrar na camada de areia/lodo dos níveis 2 e 3. Cyclograpsus integer foi registrado nos níveis 1 e 2, porém, com freqüência de sete vezes no supralitoral e apenas uma vez no mediolitoral superior. Armases angustipes e Metasesarma rubripes ocorreram exclusivamente no supralitoral (nível 1 ), com freqüência de onze e sete vezes, e densidades máximas de 1050,00 ind. $\mathrm{m}^{-3}$ e 16,67 ind. $\mathrm{m}^{-3}$, respectivamente. As densidades de A. angustipes foram as mais altas, superadas apenas por Petrolisthes armatus.

Xanthidae (Tab. I). As espécies ocorreram exclusivamente nos níveis 2, 3 e 4. Eurypanopeus abbreviatus, Panopeus americanus e Panopeus occidentalis foram de ocorrência constante durante o período estudado (no mínimo 10 vezes) nos níveis 2 e 3, ao passo que, Menippe nodifrons e Pilumnus dasypodus somente no nível 4. As três primeiras espécies mostraram freqüências iguais ou inferiores a 
cinco vezes no nível 4. Quanto à densidade, os valores foram proporcionais à freqüência de ocorrência, os quais variaram de 1,09 ind. $\mathrm{m}^{-3}$ para $M$. nodifrons no nível 2 a 257,45 ind. $\mathrm{m}^{-3}$ para $P$. dasypodus no nível 4 . Parte dos Xanthidae coletados nos níveis 2 e 3 encontrava-se enterrada na camada de areia entre as pedras e o substrato rochoso, em contraste com $P$. dasypodus que quase sempre foi observado agarrado à superfície dos cascalhos e pedregulhos submersos.

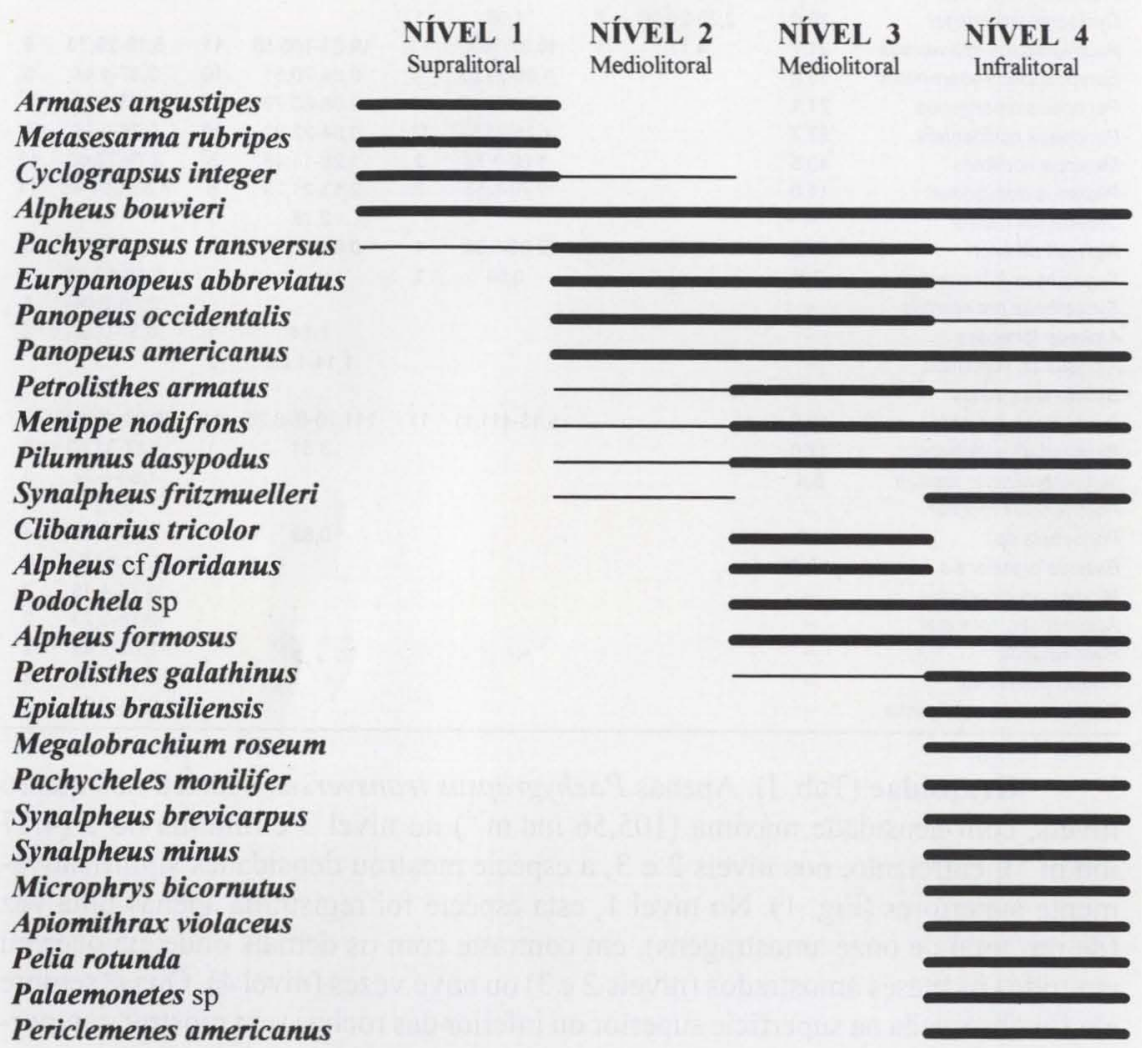

Fig. 1. Ilha do Farol, Paraná. Distribuição espacial das 27 espécies de Decapoda nos quatro níveis da praia rochosa durante o periodo estudado. As linhas espessas indicam densidades médias significativamente maiores que as linhas finas $(p<0,05)$.

Paguridae (Tab. I). A única espécie, Clibanarius tricolor (Gibbes, 1850), ocorreu apenas uma vez no nível $3 \mathrm{com}$ uma densidade de 2,78 ind. $\mathrm{m}^{-3}$.

Alpheoidea (Tab. I). Apenas Alpheus bouvieri ocorreu nos quatro níveis, embora com freqüências relativamente baixas; as densidades variaram de 1,14 ind. $\mathrm{m}^{-3}$ (nível 1) a 12,77 ind. $\mathrm{m}^{-3}$ (nível 3). Synalpheus fritzmuelleri foi a espécie mais abundante e mais frequente no nível 4 , com 10 vezes de ocorrência e 50,93 ind. $\mathrm{m}^{-3}$ de densidade máxima (nível 4); uma única ocorrência foi registrada no nível 
2 com 0,68 ind. $\mathrm{m}^{-3}$. As demais espécies foram raras e de densidades baixas: Alpheus cf. floridanus Kingsley, 1878 foi registrado duas vezes no nível 3, Alpheus formosus Gibbes, 1850 nos níveis 3 e 4 e Synalpheus minus Say, 1818 e Synalpheus brevicarpus (Herrick, 1891) somente no nível 4.

Porcellanidae (Tab. I). Somente Petrolisthes armatus foi de ocorrência constante em todos os meses nos níveis 2,3 e 4, com valores mais altos de densidade máxima registrados no presente trabalho: 411,11 ind. $\mathrm{m}^{-3}, 668,25$ ind. $\mathrm{m}^{-3}$ e 492,00 ind. $\mathrm{m}^{-3}$, respectivamente. Petrolisthes galathinus foi registrado nos níveis 3 e 4, com freqüência de uma e nove vezes, respectivamente. Foram restritos ao nível 4 Megalobrachium roseum (cinco vezes) e Pachycheles monilifer (Dana, 1852) (uma vez).

Majidae (Tab. I). Apenas Podochela sp. ocorreu em dois níveis, com freqüência de uma e quatro vezes, respectivamente. Epialtus brasiliensis, Microphrys bicornutus (Latreille, 1825), Apiomithrax violaceus (A. Milne Edwards, 1867) e Pelia rotunda A. Milne Edwards, 1875 foram de ocorrência restrita ao nível 4 , com freqüência de seis, três, duas e duas vezes, respectivamente.

Palaemonidae (Tab. I). As duas espécies registradas foram restritas ao nível 4, com freqüência de duas vezes e densidades máximas de valores baixos: 3,06 ind. $\mathrm{m}^{-3}$ para Periclemenes americanus (Kinsley, 1878) e 4,26 ind. $\mathrm{m}^{-3}$ para Palaemonetes sp.

Houve um aumento no número total de espécies registradas do nível 1 para nível 4, a saber, 5, 10, 13 e 26, respectivamente. Entretanto, a densidade máxima total dos Decapoda teve o seu máximo valor no nível $1\left(1091,98\right.$ ind. $\left.\mathrm{m}^{-3}\right)$, seguido do nível $4\left(994,76\right.$ ind. $\left.\mathrm{m}^{-3}\right)$, nível $3\left(972,97\right.$ ind. $\left.\mathrm{m}^{-3}\right)$ e nível $2\left(597,12\right.$ ind. $\left.\mathrm{m}^{-3}\right)$.

A distribuição espacial das 27 espécies de Decapoda registradas na Ilha do Farol durante o período estudado mostra que houve um aumento no número de espécies com densidades relativas altas, do nível 1 para o nível 4: 3, 5, 6 e 8, respectivamente (Fig. 1).

Somente Pachygrapsus transversus e Alpheus bouvieri ocorreram ao longo de toda extensão da transecção, embora os valores de densidade significativamente mais elevados tenham sido registrados no mediolitoral (níveis 2 e 3 ) para $P$. transversus. O único indivíduo de $A$. bouvieri registrado no nível 1 foi desprezado no cálculo das diferenças de densidade entre os níveis estudados (Tab. II).

O supralitoral pode ser caracterizado pela presença dos Grapsidae Armases angustipes, Metasesarma rubripes e Cyclograpsus integer, devido aos altos valores de densidade relativa e freqüência de ocorrência.

O mediolitoral abriga espécies totalmente distintas do supralitoral, tendo como espécies típicas da faixa (juntos os níveis 2 e 3 ) seis espécies: Pachygrapsus transversus, $P$. occidentalis, Eurypanopeus abbreviatus, Petrolisthes armatus, Clibanarius tricolor e Alpheus cf floridanus. As densidades registradas nestes dois níveis não diferem significativamente dos do nível $4 \mathrm{em}$ Panopeus americanus, Menippe nodrifrons, Pilumnus dasypodus, Podochela sp. e Alpheus formosus.

Mais da metade (10) das espécies registradas no infralitoral ocorreu exclusivamente neste nível, o que permite inferir que Majidae e Palaemonidae caracteri- 
zam a nível 4 (Tab. I). Onze espécies foram comuns com o nível 3. Quatro espécies de densidades relativas altas diminuíram significativamente os valores no infralitoral: Pachygrapsus transversus, P. occidentalis, Eurypanopeus abbreviatus e Petrolisthes armatus. Alpheus formosus manteve praticamente constante a sua densidade. Petrolisthes galathinus e Synalpheus fritzmuelleri aumentaram significativamente a densidade no infralitoral. Dentre as espécies de ocorrência exclusiva no infralitoral, apenas Epialtus brasiliensis e Megalobrachium roseum tiveram altos valores de densidade e de freqüência de ocorrência (Tab. I).

Tabela II. Ilha do Farol, Paraná. Sumário estatístico da ANOVA de Freedman, mostrando diferenças de densidade $\left(\mathrm{n}^{\circ}\right.$ ind. $\mathrm{m}^{-3}$ ) dos Decapoda nos níveis estudados. (N) Número de meses de ocorrência da espécie, (K) número de níveis onde a espécie ocorreu, (d.m.s.) diferença minima significativa, $\left(^{*}\right)$ níveis em ordem decrescente de valores médios. Letras diferentes indicam diferenças significativas para $p<0,05$.

\begin{tabular}{|c|c|c|c|c|c|c|c|}
\hline Alpheus bouvieri & 8 & 3 & 3,07943 & - & $2 a$ & $3 a$ & $4 a$ \\
\hline Menippe nodifrons & 11 & 3 & 12,7619 & 10 & $3 a$ & $4 a$ & $2 b$ \\
\hline Pachygrapsus transversus & 11 & 4 & 18,7222 & 15 & $2 a$ & $3 a 1 b$ & $4 b$ \\
\hline Panopeus americanus & 11 & 3 & 3,8571 & - & $2 a$ & $3 a$ & $4 a$ \\
\hline Petrolisthes armatus & 11 & 3 & 8,9091 & 10 & $3 a$ & $2 b$ & $4 b$ \\
\hline Pilumnus dasypodus & 11 & 3 & 10,9756 & 10 & $4 a$ & $3 a b$ & $2 b$ \\
\hline Podochela sp. & 4 & 2 & 1,0000 & - & $4 a$ & $3 a$ & \\
\hline
\end{tabular}

A figura 2 mostra a distribuição do comprimento da carapaça das espécies com densidades relativas altas nos quatro níveis estudados. O comprimento da carapaça variou de 4,3mm para Podochela sp. a 40,5mm para Menippe nodifrons (Tab. I). A maioria dos Decapoda da Ilha do Farol é representada por espécies de pequeno porte, e poucas são potencialmente comestíveis para o homem: Menippe nodifrons, Panopeus americanus, P. occidentalis e, eventualmente, Eurypanopeus abbreviatus (OLIVEIRA 1940).

A amplitude do comprimento da carapaça aumentou do nível 1 para o nível 4, acompanhando a tendência da distribuição do número de espécies. No nível 1, a referida amplitude foi de $9,5 \mathrm{~mm}(13,0 \mathrm{~mm}$ para Cyclograpsus integer a $22,5 \mathrm{~mm}$ para Armases angustipes); no nível 2, de 17,7 mm (10,0mm para Alpheus bouvieri a $27,7 \mathrm{~mm}$ para Panopeus occidentalis); nos níveis 3 e 4, de $30,5 \mathrm{~mm}(10,0 \mathrm{~mm}$ para Alpheus bouvieri a $40,5 \mathrm{~mm}$ para Menippe nodifrons). Embora a amplitude de comprimento da carapaça tenha sido a mesma para os níveis 3 e 4 , houve forte predominância de espécies de pequeno porte no nível 4 (compare a figura $2 \mathrm{com}$ a tabela I). Portanto, o tamanho da espécie de menor porte em cada faixa de maré foi uma função do tempo de emersão: animais menores predominaram em níveis com menor tempo de emersão.

\section{DISCUSSÃO}

Quando comparada com os costões rochosos de Calhetas, Pernambuco, a seqüência da composição específica da Ilha do Farol é mais próxima daquela da praia abrigada referida por CALADO \& LACERDA (1993). A nível de família dos 


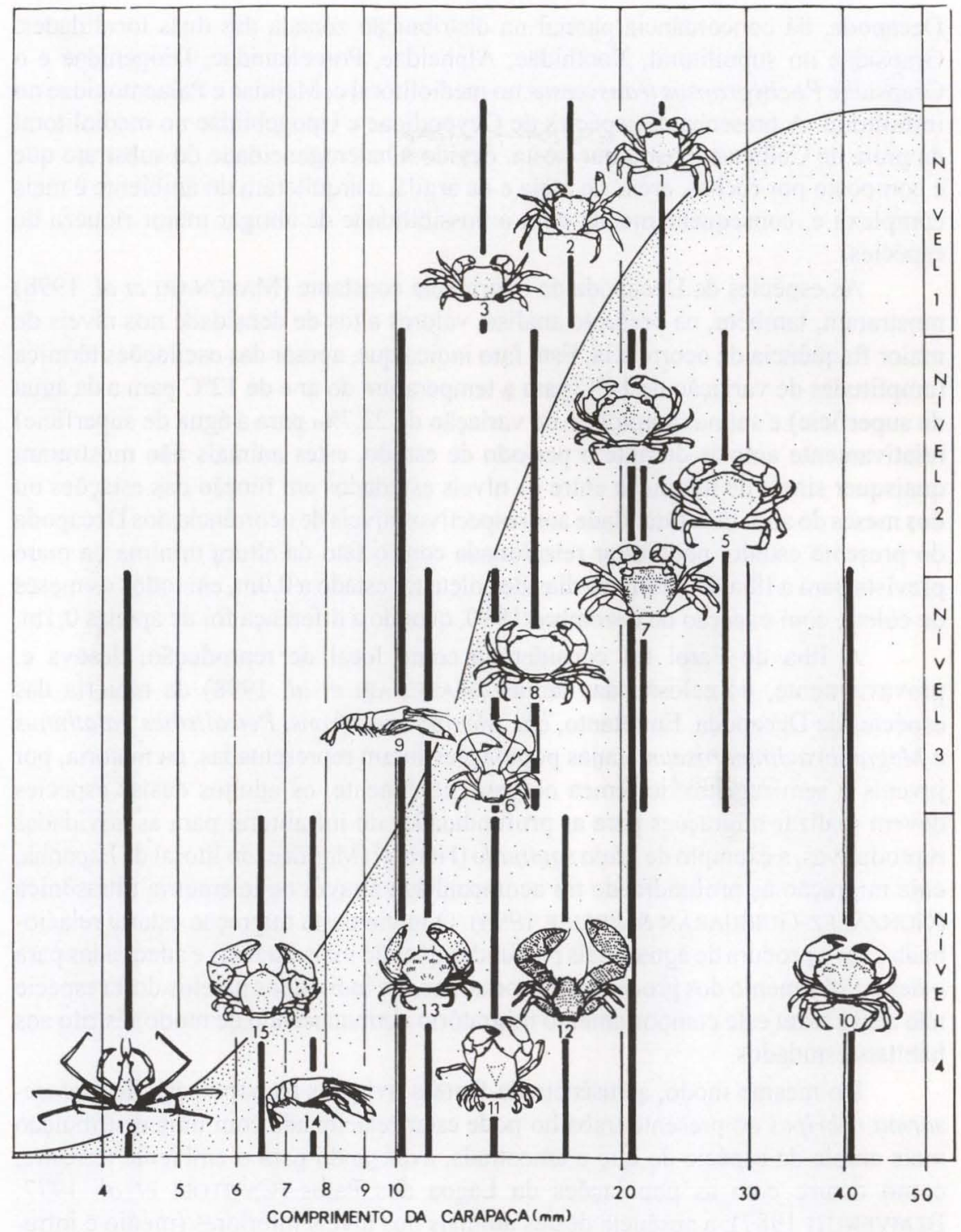

Fig. 2. Ilha do Farol, Paraná. Distribuição do comprimento da carapaça das espécies nos niveis cujas densidades são significativamente superiores $(p<0,05)$. Observar que a escala na abscissa é logarítmica. $O$ tamanho das figuras não está proporcional ao tamanho da respectiva espécie de Decapoda. (1) Armases angustipes, (2) Metasesarma rubripes, (3) Cyclograpsus integer, (4) Panopeus americanus, (5) Panopeus occidentalis, (6) Petrolisthes armatus, (7) Pachygrapsus transversus, (8) Eurypanopeus abbreviatus, (9) Alpheus bouvieri, (10) Menippe nodifrons, (11) Epialtus brasiliensis, (12) Petrolisthes galathinus, (13) Pilumnus dasypodus, (14) Synalpheus fritzmuelleri, (15) Megalobrachium roseum, (16) Podochela sp. 
Decapoda, há concordância parcial na distribuição zonada das duas localidades: Grapsidae no supralitoral, Xanthidae, Alpheidae, Porcellanidae, Diogenidae e o Grapsidae Pachygrapsus transversus no mediolitoral e, Majidae e Palaemonidae no infralitoral. A presença de espécies de Ocypodidae e Upogebiidae no mediolitoral da praia de Calhetas mostra que nesta, devido à heterogeneidade do substrato que é composto por rochas, áreas de areia e de argila, a arquitetura do ambiente é mais complexa e, consequentemente, com a possibilidade de abrigar maior riqueza de espécies.

As espécies de Decapoda de ocorrência constante (MASUNARI et al. 1998) mostraram, também, na presente análise, valores altos de densidade nos níveis de maior freqüência de ocorrência. Este fato indica que, apesar das oscilações térmica (amplitudes de variação de $14^{\circ} \mathrm{C}$ para a temperatura do ar e de $12^{\circ} \mathrm{C}$ para a da água de superfície) e salina (amplitude de variação de 22,7\% para a água de superfície) relativamente amplas durante o período de estudo, estes animais não mostraram quaisquer sinais de migração entre os níveis estudados em função das estações ou dos meses do ano. Esta fidelidade aos respectivos níveis de ocorrência dos Decapoda do presente estudo, pode estar relacionada com o fato da altura mínima da maré prevista para a Ilha do Farol nos dias de coleta ter estado a 0,0m, em todos os meses de coleta, com exceção de dezembro/1990, quando a diferença foi de apenas $0,1 \mathrm{~m}$.

A Ilha do Farol foi considerada como local de reprodução, desova e, provavelmente, de eclosão das larvas (MASUNARI et al. 1998) da maioria das espécies de Decapoda. Entretanto, em Menippe nodifrons, Petrolisthes galathinus e Megalobrachium roseum, cujas populações foram representadas, na maioria, por juvenis e sem registro de fêmea ovígera, certamente, os adultos destas espécies devem realizar migrações para as profundidades do infralitoral para as atividades reprodutivas, a exemplo de Maja squinado (Herbst) (Majidae) do litoral da Espanha, cuja migração às profundidade foi acompanhada através de telemetria ultrasônica (GONZÁLEZ-GURRIARÁN \& FREIRE 1994). O início desta migração estaria relacionada com a procura de águas mais profundas que são mais estáveis e adequadas para o desenvolvimento dos processos reprodutivos. Os indivíduos juvenis desta espécie não mostraram este comportamento migratório permanecendo de modo restrito aos hábitats estudados.

Do mesmo modo, a ausência de fềmeas ovígeras na população de Metasesarma rubripes do presente trabalho pode estar relacionada com uma distribuição mais ampla da espécie do que a amostrada, avançando para o ambiente terrestre, como ocorre com as populações da Lagoa dos Patos (CAPITOLI et al. 1977; BEMVENUTI 1987); a ausência destes animais nos níveis inferiores (medio e infralitoral) corrobora esta hipótese.

Fatores biológicos como comportamento, competição e predação constituem elementos determinantes da zonação para algumas espécies de Decapoda na zona entremarés. Pressão de predadores que leva a restringir a área de ocorrência de Decapoda foi demonstrada por meio de experimentos com gaiolas de exclusão de predadores por ENGSTROM (1984) e POSEY (1986), ao passo que, um comportamento diferenciado na utilização das conchas parece ser um dos fatores na distribuição vertical de três espécies de caranguejo-ermitão do litoral do Japão (IMAZU \& 
ASAKURA 1994). Somente através de experimentos, será possível avaliar a influência destes fatores biológicos na distribuição dos Decapoda da Ilha do Farol.

Os Decapoda registrados na Ilha do Farol são de origem marinha, pois, as larvas planctônicas necessitam de água do mar para completar o seu ciclo de vida. Mesmo dentre os Grapsidae, cujos representantes podem ser terrestres, semi-terrestres ou de águas continentais (CHACE \& HoBBS 1969), pelo menos três espécies encontradas na Ilha do Farol são classificadas como tipicamente marinhas: $P a$ chygrapsus transversus, Cyclograpsus integer e Metasesarma rubripes. Os estágios larvais destas espécies se desenvolvem na água do mar (DÍAZ \& EWALD 1968; GORE \& SCOTTO 1982). Quanto a Armases angustipes, os adultos podem ser encontrados em hábitats variados como manguezais, áreas adjacentes a rios, sumidouros marinhos e dulcícolas e na água retida nas rosetas foliares de bromélias (ABELE 1992), porém, as larvas se desenvolvem em águas salinas (ANGER et al. 1990; KowALCZUK \& MASUNARI no prelo), confirmando a total dependência da água do mar no ciclo de vida dos Decapoda da Ilha do Farol. Esta observação se contrapõe às afirmações de BARNES \& HUGHES (1988), pelo menos no que se refere aos Decapoda, de que nas faixas superiores do supralitoral no ecótono entre o ambiente terrestre e marinho há predominância de organismos de origem terrestre.

Sendo os Grapsidae fortemente eurihalinos e osmoreguladores (MANTEL \& FARMER apud STATON \& FELDER 1992), as quatro espécies desta família encontradas na Ilha do Farol são registradas na literatura como ocorrentes, também, em outros ambientes bastante variados como sedimento de manguezais, raízes ou troncos de mangues, entre raízes de Spartina sp. (Gramineae), fissuras e cavidades de trapiches e rochas, estuários, praias de pedregulhos, praias arenosas, e nas águas acumuladas nas rosetas de bromeliáceas (CHACE \& HoBBS 1969; COELHO \& RAMOS 1972; ABELE 1972; CARMO 1987; CAPITOLI et al. 1977; WILlIAMS 1984; ABELE 1992; BOSCHI et al. 1992; COBO et al. 1994 e VERGARA 1994).

Segundo GRAY (1957), caranguejos do supralitoral e níveis superiores possuem brânquias adaptadas à respiração aérea como esclerose das brânquias aliada à diminuição da área branquial, ou brânquias pequenas e firmes que mantêm a sua forma e, teoricamente, funcionam melhor fora d'água. Em algumas espécies, estruturas interlamelares servem para manter o espaçamento entre as superfícies durante a exposição ao ar (JOHNSON \& UGLOW 1985), em outras, o número de brânquias é uma função direta do nível ocupado pelo animal em relação à altura da maré ( $c f$. revisão em TAYLOR \& TAYLOR 1992). Certamente, as brânquias dos Grapsidae registrados no supralitoral do presente trabalho devem funcionar bem fora d'água. Além disso, pode-se inferir que, a camada de serapilheira neste local serviu de proteção a estes animais para evitar dessecação ou estresse térmico durante o longo período sem os respingos da maré alta. Os fios d'água provenientes da mata secundária, provavelmente, constituíram uma fonte importante de umidade nesta camada de serapilheira, já que o suprimento de água do mar ocorria somente a cada 8-12 horas, nas marés de sizígia.

No mediolitoral (considerando em conjunto os níveis 2 e 3) da Ilha do Farol, a riqueza de espécies aumenta visivelmente, quando comparada com a do supralitoral. Esta riqueza está relacionada com a complexidade do habitat, onde estão presentes elementos como areia, argila e rochas de tamanhos variados que se 
assentam sobre o substrato primário rochoso. Esta complexidade na arquitetura do mediolitoral é, também, um fator que ameniza o impacto das ondas, propiciando um ambiente de abrigo contra as correntezas durante as marés altas (HARTNOLL 1983) e contra dessecação e estresse térmico nas vazantes (ABELE et al. 1986; AGNEW \& TAYLOR 1986). O dois níveis do mediolitoral diferem tanto no número como na composição de espécies, entretanto, a lista das espécies de densidades relativas altas é praticamente a mesma (Fig. 1). Por outro lado, a presença de três espécies em comum entre o nível 3 e o 4, permite supor que o nível 3 é capaz de abrigar maior número de animais sensíveis aos estresses de emersão que o nível 2.

Foi possível discriminar três tipos básicos de estratégia contra os estresses abióticos decorrentes da emersão dentre os Decapoda do mediolitoral da Ilha do Farol. O primeiro grupo é constituído por Panopeus occidentalis, Panopeus americanus e Eurypanopeus abbreviatus os quais passam o período de emersão protegidos nos espaços entre as pedras e, frequentemente, enterrados na areia e lodo úmidos retidos entre os cascalhos sobre o substrato rochoso, conforme a literatura abaixo mencionada sobre a biologia das referidas espécies.

OLIVEIRA (1940) descreve P. occidentalis como uma espécie fossorial de maguezais, cujas tocas podem atingir $30 \mathrm{~cm}$ ou mais de profundidade. De hábito omnívoro, estes animais são incapazes de nadar, seus movimentos são lentos e se escondem em locais mais escuros. $\mathrm{O}$ autor acredita que $P$. occidentalis tenha poucos predadores devido à carapaça endurecida destes animais. Outros hábitats como baixios de lama, superfície de rochas, esponjas, ascídias, algas macroscópicas e amontoados de pilares são registrados na literatura como locais de ocorrência da espécie (INGLE 1985; WILLIAMS 1984).

A ocorrência de Panopeus americanus está associada, na maioria dos casos, com um substrato arenoso/lodoso e, portanto, a espécie teria uma biologia mais próxima a Panopeus occidentalis (OLIVEIRA 1940) do que outras de grupos diferentes. Da mesma forma, outros ambientes de ocorrência são conhecidos: desembocaduras de rios, manguezais, sob rochas, esponjas e feixes de briozoários, praias arenosas e rochas adjacentes (RATHBUN 1930; NEGREIROS-FrANSOZO 1986a). $P$. americanus poderia pertencer ao segundo grupo de estratégias tratado, pois, a literatura não menciona qualquer hábito fossorial deste caranguejo. Portanto, uma classificação definitiva está condicionada ao conhecimento completo da biologia da referida espécie.

Eurypanopeus abbreviatus é conhecido do mesmo habitat mencionado para Panopeus americanus por RATHBUN (1930). Ocorre, também, em poças-de-maré e em praias sob influência de água doce (NEGREIROS-FrANSOZo 1986b). No estrangeiro, espécies congêneras são conhecidas como "mud crabs" (GARCÉs 1987), numa alusão ao habitat lodoso em que vivem.

O segundo grupo do mediolitoral habita preferencialmente os espaços entre as pedras ou na superfície inferior dos matacões e cascalhos da Ilha do Farol, que é protegida contra a insolação direta ou desidratação, sem no entanto, enterrar-se na camada areno-lodosa. Pertencem a este grupo Pachygrapsus transversus, Petrolisthes armatus e adultos de Menippe nodifrons; entretanto, há tolerâncias fisiológicas contrastantes entre as referidas espécies. 
Pachygrapsus transversus foi a única espécie observada capaz de se expor sobre a superfície superior dos matacões e pedregulhos. Este hábito pode ser explicado pela grande versatilidade da espécie na regulação iônica e osmótica em condições de variação de salinidade e desidratação (WARBURG et al. 1987). A referida espécie, ainda, mostrou uma distribuição distinta dos demais representantes da família no presente trabalho (Fig. 1). Como ela é encontrada em vários ecossistemas como estuários e recifes, rochas do entremarés, pilares, raízes e sedimentos de manguezais, praias arenosas e tronco de árvores (COELHO \& RAMOS 1972; WILLIAMS 1984; CARMO 1987), pode-se inferir que a espécie pode viver em qualquer hábitat entremarés que ofereça abrigo como fissuras e buracos onde $o$ caranguejo encontra abrigo para aliviar o estresse térmico e de desidratação durante a maré baixa (ABELE et al. 1986; AGNEW \& TAYLOR 1986). Esta estratégia de $P$. transversus concorda com a taxa mais rápida de perda de água medida em laboratório, quando comparada com outras espécies semi-terrrestres de porte maior como Ocypode quadrata (Fabricius, 1787) (Ocypodidae), Goniopsis cruentata (Latreille, 1803) (Grapsidae) e Ucides cordatus (Linnaeus, 1763) (Ocypodidae) (SANTOS et al. 1986).P. transversus é residente da zona entremarés, pois, durante as marés altas ela permanece inativa em fissuras até a próxima maré baixa (ABELE et al. 1986), e, portanto, não realiza migrações para as profundidades.

Num estudo comparativo de tolerância à salinidade entre quatro espécies de Decapoda provenientes da região de São Sebastião, São Paulo, foi provado que Petrolisthes armatus é a espécie mais estenohalina e Pachygrapsus transversus a mais eurihalina (SHUMWAY 1983). Como P. armatus nunca foi observado em atividade nas superfícies expostas do mediolitoral, o hábito de permanecer nas áreas protegidas da insolação e desidratação deve ter evitado alterações significativas a nível osmótico nos indivíduos da referida espécie. Entretanto, como esta população foi abundante, também no nível superior do mediolitoral, onde a exposição à dessecação variou de 4-8 horas durante um ciclo de maré, uma certa capacidade de osmoregulação da espécie deverá existir, a exemplo de Petrolisthes elongatus (Milne Edwards, 1837) dos estuários da Nova Zelândia. A ausência de $P$. elongatus nos níveis superiores é atribuída ao hábito suspensívoro da espécie, a qual necessita de um tempo mínimo de submersão para obter alimentação (JONES \& GREENWOOD 1982). Embora em condições de submersão $P$. armatus seja um ativo suspensívoro, a abundância destes animais no mediolitoral superior da Ilha do Farol permite inferir que, outras fontes de alimento como detritos do substrato obtidos por raspagem do substrato sejam até mais importantes do que a matéria orgânica suspensa e plancton que são obtidos por filtração (CAINE 1975). Esta versatilidade no hábito alimentar da espécie parece ser a adaptação mais influente nas altas densidades registradas no presente trabalho. A diversidade de hábitats citada por VELOSO \& MELO (1993) corrobora esta assumpção.

Considerada uma espécie carnívora por BERT (1986), Menippe nodifrons não possui características branquiais de respiração aérea a nível de Trichodactylus petropolitanus (Göldi, 1886) (Trichodactylidae) ou de Ucides cordatus (Linnaeus, 1763) (Ocypodidae) (SANTOS et al. 1985) e, portanto, um abrigo contra perda de água parece ser fundamental na existência desta espécie em áreas entremarés. Praias 
rochosas parecem constituir o substrato preferido da espécie como foi observado por FRANSOzO et al. (1988) na captura de fêmeas ovígeras da espécie, mas, é observado, também, em recifes no estrangeiro (BERT 1986). A escassez de indivíduos adultos desta espécie no presente estudo, pode estar relacionada com a necessidade dos mesmos de um espaço maior existente entre os grandes blocos rochosos como local de refúgio, espaço este não analisado no presente estudo, devido a impossibilidade de deslocar tais blocos. Uma sobrepesca da espécie pelo homem pode ter sido, também, a causa da baixa densidade dos exemplares adultos. Conhecida vulgarmente como "guaiá" ou "caranguejo-de-pedra" (OLIVEIRA 1940), ela é uma das raras espécies que atingem um tamanho suficiente para consumo humano no hábitat estudado.

A terceira estratégia é observada pelo grupo de Pilumnus dasypodus, juvenis de Menippe nodifrons, Podochela sp., Petrolisthes galathinus e Synalpheus fritzmuelleri. Certamente vulneráveis à dessecação, estes animais de pequeno porte (Fig. 2) permanecem agarrados à superfície úmida das pedras, as quais frequentemente estão cobertas por uma camada de algas filamentosas que incrementam o teor de umidade neste microhábitat. A favor desta hipótese está o registro de maiores densidades destes animais no infralitoral (Fig. 2). Os representantes deste grupo foram capturados principalmente no processo de lavagem das pedras ( $c f$. Material e Métodos em MASUNARI et al. 1998).

Alpheus bouvieri também pertence a este último grupo, porém, as densidades mais altas foram observadas no mediolitoral, em contraste com as espécies acima tratadas. Ela constitui, também, uma das duas espécies que ocorreram em todos os níveis estudados (a outra é Pachygrapsus transversus), mostrando grande habilidade nas regulações fisiológicas em condições de emersão e submersão, a exemplo de Alpheus viridari (Armstrong, 1949) que habita a rozosfera dos manguezais do litoral da Califórnia, E.U.A. (FERRARIS et al. 1994).

Comportamentos migratórios ontogênicos como foi observado em Menippe nodifrons da Ilha do Farol são comuns entre vários Decapoda. De uma forma geral, os juvenis distribuem-se ao longo de toda zona entremarés, ao passo que, os adultos se limitam a uma determinada faixa, geralmente o infralitoral (GRIFFIN 1971; DEPLEDGE 1984; WARMAN et al. 1993).

O registro da riqueza máxima de espécies no infralitoral (quase o dobro do nível 3) indica que, onde não há estresse térmico ou de dessecação, maior número de espécies é capaz de realizar as suas funções vitais. As espécies ocorrentes nesta faixa, principalmente aquelas que o fazem exclusivamente, certamente não suportariam qualquer emersão, sob o risco de perda da vitalidade. Nesta faixa, a presença do cinturão de Sargassum e Hypnea condiciona a ocorrência de animais intimamente relacionados com as mesmas, como Epialtus brasiliensis (RATHBUN 1925; NEGREIROS-FRANSOZO \& FRANSOZO 1991) e Mycrophrys bicornutus (KILAR \& LOU 1984; CARMONA-SUAREZ 1992; NEgREIROS-FRANSOZO et al. 1994).

A diminuição do tamanho das espécies em função inversa com o tempo de emersão da faixa de ocorrência observada nos Decapoda da Ilha do Farol (Fig. 2) está associada à perda de líquido corpóreo mais rápida em animais menores (relação superfície/volume maior) como foi observado em várias espécies de Decapoda 
(Jones \& GREENWOOd 1982; PELlegrino 1984; SANTOS et al. 1986), ou uma sobrevida mais curta em condições de dessecação (YoUNG 1978) do que animais maiores. Embora Menippe nodifrons, a espécie de maior porte registrado no presente estudo, tenha mostrado como nível de maior importância o infralitoral, indivíduos de tamanho máximo para a espécie foram registrados somente no mediolitoral superior. No infralitoral esta espécie está representada exclusivamente por juvenis de pequeno porte e, portanto, vulneráveis à perda de líquido em condições de emersão.

Os hábitos alimentares das espécies ocorrentes no infralitoral são diversificados, incluindo os filtradores/omnívoros como Petrolisthes armatus (CAINE 1975); carnívoros como Menippe nodifrons (BERT 1986); omnívoros ou predadores-necrófagos facultativos, consumindo, também, diatomáceas e algas macroscópicas como Pilumnus dasypodus (Williams 1984); omnívoros com $90 \%$ de algas, mas também, esponjas, poliquetos e briozoários como Mycrophrys bicornutus (KILAR \& LOU 1984) e, provavelmente, como Podochela sp.; predador e herbívoro como os Alpheidae (KAESTNER 1970); prováveis filtradores como Megalobrachium roseum e Pachycheles monilifer, e carnívoros-necrófagos como os Palaemonidae.

A esta diversidade alimentar acrescenta-se a multiplicidade de hábitos que aumentam a sobrevida das espécies do infralitoral que são de pequeno porte e, portanto, presas em potencial: 1) camuflagem por meio de fixação de algas ou esponjas na face superior da carapaça e dos pereiópodos como Microphrys bicornutus, Podochela sp., Apiomithrax violaceus e Pelia rotunda, presença de cerdas finas e flexíveis na face superior da carapaça e dos pereiópodos que facilitam a retenção de sedimento fino escuro dificultando a visualização do predador como Pilumnus dasypodus e capacidade de mudar a cor do corpo de acordo com a alga-substrato como Epialtus brasiliensis (RATHBUN 1925; MELO et al. 1989); 2) capacidade de construir tubos com restos vegetais ou no substrato mole como representantes de Alpheidae (KAESTNER 1970); 3) corpo muito achatado dorsoventralmente para melhor aderência em substratos sólidos como as espécies de Porcellanidae; e 4) corpo transparente e movimentos rápidos dentre os Palaemonidae. Pressão de predadores que leva a restringir a área de ocorrência de Decapoda foi demonstrada por meio de experimentos com gaiolas de exclusão de predadores por ENGSTROM (1984) e POSEY (1986); em ambos os casos, o predador é um peixe. Certamente, a soma das diversidades adaptativas acima mencionadas induzem, pelo menos em parte, a uma diminuição da competição interespecífica dos Decapoda, permitindo a coexistência de maior número de espécies.

A distribuição nitidamente excludente por um lado de Armases angustipes, Cyclograpsus integer e Metasesarma rubripes, no supralitoral, e de Pachygrapsus transversus, no médio e infralitoral, permite supor que $P$. transversus e $A$. angustipes (as espécies mais abundantes) realizam uma repartição do recurso espaço na exploração de alimento. Embora ambas as espécies sejam omnívoras, a dieta natural de $A$. angustipes inclui itens alimentares tipicamente terrestres como insetos, restos de vegetais vasculares e tricomas de bromeliáceas (ABELE 1992), em contraste com $P$. transversus que se alimenta de algas, porcelanídeos e peixes, mostrando uma dieta de origem marinha (Williams 1984; ABELE et al. 1986). O hábito de $P$.

Revta bras. Zool. 15 (3): 643 - 664, 1998 
transversus pastar sobre tapetes de microalgas que crescem sobre as superfícies lisas de rochas (ABELE et al. 1986) corrobora esta assumpção, pois, este hábito não seria possível nos níveis supralitorais. O trabalho de JONES (1972) com duas espécies de Ocypode (Ocypodidae), a quais mantêm zonas distintas de distribuição em função das diferenças na dieta e na atividade locomotora, corrobora esta hipótese.

A ocorrência de Panopeus americanus, P. occidentalis e Eurypanopeus abbreviatus tanto no mediolitoral como no infralitoral indica que neste último nível há condições mínimas de existência destas espécies. Entretanto, as densidades visivelmente inferiores indicam que o mediolitoral apresenta melhores condições para as mesmas, as quais podem ser a presença de areia e lodo acumulados entre os cascalhos. Outros fatores, como competição com outras espécies fisiologicamente superiores nos níveis infralitorais, não podem ser descartadas, pois, o referido grupo tem o mediolitoral como local de reprodução e, portanto, são residentes deste nível.

A coexistência das três espécies de Xanthidae acima referidas associadas ao substrato areno-lodoso do mediolitoral, aliada à semelhança na distribuição de densidade das mesmas, indica a necessidade urgente de um estudo da biologia e do hábito destes animais, visto que os recursos naturais como fontes de alimento e espaço, certamente, são limitantes nesta faixa entremarés (mediolitoral). Experimentos de exclusão na natureza deverão trazer conhecimentos importantes no que concerne às interações interespecíficas destas espécies.

A predominância de Alpheus bouvieri e Synalpheus fritzmuelleri em faixas distintas indica maior suscetibilidade à dessecação desta última espécie, provavelmente devido ao menor tamanho do que a primeira. Outro aspecto a considerar é que, se estas espécies seguem a tendência da família no hábito alimentar (predador e consumidor de algas) (KAESTENER 1970), pode-se pensar numa possível repartição de área de exploração de alimento.

De uma forma geral, a distribuição diferenciada dos Decapoda observada ao longo do substrato rochoso da Ilha do Farol está relacionada com as características físicas intrínsecas de cada nível onde o animal se encontra durante o período de emersão, e com a biologia e/ou hábito do referido animal. Esta observação está baseada no fato de que, com raras exceções, as espécies registradas no presente trabalho, não são de ocorrência exclusiva em praias de substrato rochoso e sim, de uma variedade muito grande de habitats, especialmente de mangezais. Excluindo as espécies típicas de infralitoral rochoso como Menippe nodifrons (MELO et al. 1989) e representantes de Porcellanidae, as demais foram registradas em ambientes diferentes de praias rochosas, sugerindo que a praia rochosa da Ilha do Farol reúne características ambientais mistas entre serapilheira, costões rochosos, substrato lodoso e fital.

Considerada a densidade relativa em cada nível de ocorrência, pode-se dizer que o supralitoral da Ilha do Farol é caracterizado pela presença de uma associação de Decapoda com respiração principalmente aérea, enquanto no mediolitoral, os animais possuem diferentes estratégias adaptativas contra os estresses térmicos e de desidratação. No infralitoral, animais pequenos vulneráveis às condições de emersão disputam o espaço com modos de vida e hábitos alimentares muito diversificados.

Revta bras. Zool. 15 (3): 643 - 664, 1998 
Conhecidas a composição e distribuição das espécies de Decapoda da Ilha do Farol, faz-se necessário um estudo autoecológico das mesmas e desvendar as interações biológicas responsáveis pela distribuição espacial por meio de experimentos.

AGRADECIMENTOS. Ao Prof. Dr. Gustavo A.S. de Melo, Museu de Zoologia, Universidade de São Paulo, São Paulo, pela confirmação de identificação das espécies de Decapoda Brachyura constantes do presente trabalho, bem como pelo envio de espécimes depositados no referido Museu. Ao biólogo Marcelo M. Braga, responsável pelo Laboratório de Invertebrados, Museu do Capão da Imbuia, Curitiba, Paraná, pelo empréstimo de espécimes de Decapoda depositados no referido Museu. Ao biólogo André H.G. Sicuro e ao Prof. Dr. Joaquim O. Branco, Universidade do Vale do Itajai, Itajai, Santa Catarina, pelo precioso auxílio nos trabalhos de coleta do material biológico. Ao Dr. Luís A. Foerster, Departamento de Zoologia, Universidade Federal do Paraná, pela correção do abstract.

\section{REFERÊNCIAS BIBLIOGRÁFICAS}

ABELE, L.G. 1972. A note on the brazilian bromeliad crabs (Crustacea Grapsidae). Arq. Ciên. Mar., Fortaleza, 12 (2): 123-126.

1992. A review of the grapsid crab genus Sesarma (Crustacea: Decapoda: Grapsidae) in America, with the description of a new genus. Smithson. Contr. Zool. 527: 1-60.

ABELE, L.G.; P.J. CAMPANELla \& M. SAlmon. 1986. Natural history and social organization of the semiterrestrial grapsid crab Pachygrapsus transversus (Gibbes). Jour. Exp. Mar. Biol. Ecol. 104: 153-170.

ABELE, L.G. \& W. KIM. 1989. The decapod crustaceans of the Panama Canal. Smithson. Contr. Zool. 482: 1-50.

AGNEW, D.J. \& A.C. TAYLOR. 1986. Effects of oxygen tension, temperature, salinity, and humidity on the survival of two intertidal gammarid amphipods. Mar. Ecol. 32: 27-33.

ANGER, K.; J. HARMS; M. MONTÚ \& C. BAKKER. 1990. Effects of salinity on the larval development of a semiterrestrial tropical crab, Sesarma angustipes (Decapoda: Grapsidae). Mar. Ecol. Progr. Ser. 62: 89-94.

BARNES, R.S.K. \& R.N. HUGHES. 1988. An introduction to marine ecology. London, Blackwell, 351p.

BEMVENUTI, C.E. 1987. Macrofauna bentônica da região estuarial da Lagoa dos Patos, RS, Brasil. In: I Simpósio sobre Ecossistemas da Costa Sul e Sudeste Brasileira; síntese dos conhecimentos. São Paulo, Publicações ACIESP, 54-I: 428-459.

BERT, T.M. 1986. Speciation in western Atlantic stone crabs (genus Menippe): the role of geological processes and climatic events in the formation and distribution of species. Mar. Biol. 93: 157-170.

BosCHI, E.E.; C.E. FisCHBACH \& M.I. IorIo. 1992. Catalogo ilustrado de los crustaceos estomatopodos y decapodos marinos de Argentina. Frente Maritimo 10, sec. A: 7-94.

CAINE, E.A. 1975. Feeding and mastigatory structures of selected Anomura (Crus- 
tacea). Jour. Exp. Mar. Biol. Ecol. 18: 277-301.

CALADO, T.C. \& P.R. LACERDA. 1993. Zonação vertical e variação sazonal da carcinofauna (Decapoda e Isopoda) do costão rochoso de Calhetas (Cabo-Pernambuco-Brasil). Arq. Biol. Tecnol. 36 (4): 731-738.

CAPITOLI, R.R.; C.E. BEMVEnUti \& N.M. GianUCA. 1977. Ocorrência e observações bio-ecológicas do caranguejo Metasesarma rubripes (Rathbun) na região estuarial da Lagoa dos Patos. Atlantica, Rio Grande, 2 (1): 50-62.

CARMO, T.M.S. 1987. Os manguezais ao norte da Baía de Vitória, Espírito Santo. In: I Simpósio sobre Ecossistemas da Costa Sul e Sudeste Brasileira: síntese dos conhecimentos. São Paulo, Publicações da ACIESP, 54-I: 173-194.

CARMONA-SUAREZ, C.A. 1992. Interpopulation size variation in a tropical decorator crab, Microphrys bicornutus (Latreille, 1825) (Decapoda, Brachyura, Majidae). Crustaceana 63 (3): 319-322.

CHACE JR., F.A. \& H.H. HobBS JR. 1969. The freshwater and terrestrial decapod crustaceans of the West Indies with special reference to Dominica. U.S. Nat. Mus. Bull. 292: 1-258.

Christoffersen, M.L. 1979. Campagne de la Calypso au large des côtes atlantiques de l'Amérique du Sud (1961-1962). 36. Decapod Crustacea: Alpheoida. Résult. Scient. Camp. Calypso (11): 297-377.

Cobo, V.J.; A. Fransozo; F.L.M. Mantelatto; M.A.A. Pinheiro; S. SAntos \& J.M. GóES. 1994. Composição dos braquiúros (Crustacea, Decapoda) no manguezal formado pelos rios Comprido e Escuro, Ubatuba, SP. In: III Simpósio de Ecossistemas da Costa Brasileira: subsídios a um gerenciamento ambiental. São Paulo, Publicações da ACIESP, 87-I: 146-150.

CoElho, P.A. \& M.A. RAMOS. 1972. A constituição e a distribuição da fauna de decápodos do litoral leste da América do Sul entre as latitudes de $5^{\circ} \mathrm{N}$ e $39^{\circ} \mathrm{S}$. Trabls. Oceanogr. Univ. Fed. Pernambuco, Recife, 13: 133-236.

CONNELL, J.H. 1961. Effects of competition, predation by Thais lapillus, and other factors on natural populations of the barnacle Balanus balanoides. Ecol. Monogr. 31: 61-104.

DePledGe, M.H. 1984. The influence of aerial exposure on gas exchange and cardiac activity in the shore crab, Carcinus maenas (L.). Comp. Biochem. Physiol. 79A (3): 339-344.

DHN. 1990. Tábua das marés. Rio de Janeiro, Diretoria de Hidrografia e Navegação, Marinha do Brasil, DG 16-27, 231p.

. 1991. Tábua das marés. Rio de Janeiro, Diretoria de Hidrografia e Navegação, Marinha do Brasil, DG 16-28, 181 p.

DíAz, H. \& J.J. EwALD. 1968. The larval development of Metasesarma rubripes (Rathbun) and Sesarma ricordi H. Milne Edwards (Brachyura, Grapsidae) reared under laboratory conditions. Crustaceana (Suppl. 2): 225-248.

DWORSCHAK, P.C. 1987. The biology of Upogebia pusilla (Petagna) (Decapoda, Thalassinidea) II. Environments and zonation. Mar. Ecol. 8 (4): 337-358.

EngSTROM, N.A. 1984. Depth limitation of a tropical intertidal xanthid crab, Cataleptodius floridanus, and a shallow-water majid, Pitho aculeata: results of a caging experiment. Jour. Crust. Biol. 4: 55-62.

Ferraris, J.D.; K. Fauchald \& B. Kensley. 1994. Physiological responses to 
fluctuation in temperature or salinity in invertebrates. Adaptations of Alpheus viridari (Decapoda, Crustacea), Terebellides parva (Polychaeta) and Golfingia cylindrata (Sipunculida) to the mangrove habitat. Mar. Biol. 120: 397-406.

Fransozo, A.; M.L. Negreiros-Fransozo \& C.M. HiYodo. 1988. Développement juvénile de Menippe nodifrons Stimpson, 1859 (Crustacea, Decapoda, Xanthidae) au laboratoire. Rev. Hydrobiol. Trop. 21 (4): 297-308.

GARCÉS, H.A.,B. 1987. Comparative behavior of Eurypanopeus depressus (Smith) and Eurypanopeus dissimilis (Benedict and Rathbun) (Decapoda: Brachyura: Xanthidae). Rev. Biol. Trop. 35 (2): 173-181.

GONZÁlEZ-GuRRIARÁN, E. \& J. FrEIRE. 1994. Movement patterns and habitat utilization in the spider crab Maja squinado (Herbst) (Decapoda, Majidae) measured by ultrasonic telemetry. Jour. Exp. Mar. Biol. Ecol. 184: 269-291.

GoRE, R.H. \& L.E. SCOTTO. 1982. Cyclograpsus integer H. Milne Edwards, 1837 (Brachyura: Grapsidae): the complete larval development in the laboratory, with notes on larvae of the genus Cyclograpsus. Fish. Bull. 80 (3): 501-521.

GRAY, I.E. 1957. A comparative study of the gill area of crabs. Biol. Bull. Mar. Biol. Lab., Woods Hole, 112: 34-42.

GRIFFIN, D.J.G. 1971. The ecological distribution of grapsid and ocypodid shore crabs (Crustacea: Brachyura) in Tasmania. Jour. Anim. Ecol. 40: 597-621.

GRIFFITHS, C.L. \& G.M. BRANCH. 1991. The macrofauna of rocky shore in False Bay. Trans. Roy. Soc. S. Afr. 47 (4-5): 575-594.

HANEKOM, N. \& T. ERASMUS. 1988. Variations in size compositions of populations of Upogebia africana (Ortmann) (Decapoda, Crustacea) within the Swartkops estuary and possible influencing factors. S. Afr. Jour. Zool. 23 (4): 259-265.

HARTNOLL, R.G. 1983. Substratum, p.97-124. In: R. EARLL \& D.G. ERWIN (Eds). Sublittoral ecology. New York, Oxford Univ. Press, VI+277p.

ICELY, J.D. \& D.A. JONES. 1978. Factors affecting the distribution of the genus Uca (Crustacea: Ocypodidae) on an East African shore. Estuar. Coast. Mar. Scienc. 6: 315-328.

IMAZU, M. \& A. ASAKURA. 1994. Distribution, reproduction and shell utilization patterns in three species of intertidal hermit crabs on a rocky shore on the Pacific coast of Japan. Jour. Exp. Mar. Biol. Ecol. 184: 41-65.

INGLE, R.W. 1985. Larval development of the mud crab Panopeus occidentalis de Saussure, from Bermuda (Crustacea: Xanthoidea: Panopeidae). Bull. Br. Mus. Nat. Hist. (Zool.) 48 (4): 233-248.

JENSEN, G.C. \& D.A. ARMSTRONG. 1991. Intertidal zonation among congeners: factors regulating distribution of porcelain crabs Petrolisthes spp. (Anomura: Porcellanidae). Mar. Ecol. Progr. Ser. 73: 47-60.

JOHNSON, I. \& R.F. UGLOW. 1985. Some effects of aerial exposure on the respiratory physiology and blood chemistry of Carcinus maenas (L.) and Liocarcinus puber (L.). Jour. Exp. Mar. Biol. Ecol. 94: 151-165.

JONES, D.A. 1972. Aspects of the ecology and behaviour of Ocypode ceratophthalmus (Pallas) and O. kuhlii de Haan (Crustacea: Ocypodidae). Jour. Exp. Mar. Biol. Ecol. 8: 31-43.

Jones, M.B. \& J.G. GreENwOOD. 1982. Water loss of a porcelain crab, Petrolisthes elongatus (Milne Edwards, 1837) (Decapoda, Anomura) during atmospheric 
exposure. Comp. Biochem. Physiol. 72A (4): 631-636.

KAESTNER, A. 1970. Invertebrate Zoology. Vol. III. Crustacea. New York, Interscience, VII+523p.

KENSLER, C.B. 1967. Desiccation resistance of intertidal crevice species as a factor in their zonation. Jour. Anim. Ecol. 36: 391-406.

KILAR, J.A. \& R.M. LoU. 1984. Ecological and behavioral studies of the decorator crab, Microphrys bicornutus Latreille (Decapoda: Brachyura): a test of optimum foraging theory. Jour. Exp. Mar. Biol. Ecol. 74: 157-167.

KowalczuK, V.G.L. \& S. Masunari (no prelo). The larval development of Armases angustipes (Dana, 1852) (Decapoda: Brachyura: Grapsidae) under laboratory conditions. Invertebrate Reproduction and Development.

LEVINTON, J.S. 1982. Marine Ecology. New Jersey, Prentice-Hall, XV+526p.

LIVELY, C.M.; P.T. RAIMONDI \& L.F. DELPH. 1993. Intertidal community structure: space-time interactions in the northern Gulf of California. Ecology 74 (1): 162-173.

Masunari, S.; E. Oliveira \& V.G.L. KowalczUK. 1998. Crustacea Decapoda da praia rochosa da Ilha do Farol, Matinhos, Paraná. I. Distribuição temporal de densidade das populações. Revta bras. Zool. 15 (1): 219-239.

Melo, G.A.S.; V.G. Veloso \& M.C. Oliveira. 1989. A fauna de Brachyura (Crustacea, Decapoda) do litoral do Estado do Paraná. Lista preliminar. Nerítica, Pontal do Sul, 4 (1/2): 1-31.

Negreiros-Fransozo, M.L. 1986a. Desenvolvimento pós-embrionário de Panopeus americanus Saussurre, 1857 (Decapoda, Xanthidae), em laboratório. Rev. Brasil. Biol. 46 (1): 173-188.

1986b. Desenvolvimento pós-embrionário de Eurypanopeus abbreviatus (Stimpson, 1860) (Crustacea, Decapoda, Xanthidae), em laboratório. Bolm Zool. USP, São Paulo, 10: 19-39.

NEgreiros-Fransozo, M.L. \& A. Fransozo. 1991. Larval stages of Epialtus brasiliensis Dana, 1852 (Decapoda, Brachyura, Majidae) reared in the laboratory, with notes on characters of the majid subfamilies. Crustaceana 60 (2): 200-212.

Negreiros-Fransozo, M.L.; A. Fransozo \& A.L.D. ReigadA. 1994. Biologia populacional de Epialtus brasiliensis Dana, 1852 (Crustacea, Majidae). Rev. Brasil. Biol. 54 (1): 173-180.

Oliveira, E. \& S. Masunari. 1995. Estrutura populacional de Petrolisthes armatus (Gibbes) (Decapoda, Anomura, Porcellanidae) da Ilha do Farol, Matinhos, Paraná, Brasil. Rev. bras. Zool. 12 (2): 355-371.

OLIVEIRA, L.P.H. 1940. Observações preliminares sobre a biologia dos Crustáceos do gênero Panopeus Milne Edwards, 1834. Mem. Inst. Oswaldo Cruz, Rio de Janeiro, 35 (1): 153-171.

PAULA, E.J. 1987. Zonação nos costões rochosos: região entre-marés. In: I Simpósio sobre Ecossistemas da Costa Sul e Sudeste Brasileira; síntese dos conhecimentos. São Paulo, Publicações ACIESP nº 54-1: 266-288.

PELLEGRINO, C.R. 1984. The role of desiccation pressures and surface area/volume relationships on seasonal zonation and size distribution of four intertidal decapod Crustacea from New Zealand: implications for adaptation to land. Crusta- 
ceana 47 (3): 251-268.

PETRAITIS, P.S. 1987. Factors organizing rocky intertidal communities of New England: herbivory and predation in sheltered bays. Jour. Exp. Mar. Biol. Ecol. 109: 117-136.

PoseY, M.H. 1986. Predation on a burrowning shrimp: distribution and community consequences. Jour. Exp. Mar. Biol. Ecol. 103: 143-161.

Rathbun, M.J. 1925. The spider crabs of America. U.S. Nat. Mus. Bull. 129: 1-613.

Portunidae, Atelecyclida, Cancridae andXanthida. U.S. Nat Mus. Bull. 152: 1-609.

SANTOS, M.C.F.; M. ENGELFTEIN \& M.A. GABRIELLI. 1985. Relationships concerning respiratory devices in crabs from different habitats. Comp. Biochem. Physiol. 81A (3): 567-570.

SANTOS, M.C.F.; S.O. SuAdiCANI; B.R. MARTINEZ \& E.S. LobO. 1986. Rates of water loss in four crabs from different habitats. Comp. Biochem. Physiol. 85A (2): 309-312.

SHUMWAY, S.E. 1983. Oxygen consumption and salinity tolerance in four Brazilian crabs. Crustaceana 44 (1): 76-82.

Silva, B.M.G.; A.C. BragA \& F. D’InCAO. 1989. Porcellanidae (Decapoda, Anomura) de Santa Catarina e Rio Grande do Sul, Brasil. Iheringia, sér. Zool., Porto Alegre, (69): 131-146.

STATON, J.L. \& D.L. FELDER. 1992. Osmoregulatory capacities in disjunct Western Atlantic populations of the Sesarma reticulatum complex (Decapoda: Grapsidae). Jour. Crust. Biol. 12 (3): 335-341.

TAYLOR, H.H. \& E.W. TAYLOR. 1992. Gills and lungs: the exchange of gase and ions, p.203-293. In: F.W. HARrison \& A.G. HumES (Eds). Microscopic anatomy of invertebrates. 10. Decapod Crustacea. New York, Wiley-Liss, $\mathrm{XIV}+459 \mathrm{p}$.

TEAL, J.M. 1958. Distribution of fiddler crabs in Georgia salt marshes. Ecology 39 (2): 185-193.

Veloso, V.G. \& G.A.S. MELo. 1993. Taxonomia e distribuição da família Porcellanidae (Crustacea, Decapoda, Anomura) no litoral brasileiro. Iheringia, Sér. Zool., Porto Alegre, (75): 171-186.

VERGARA FILHO, W.L. 1994. Composição e distribuição dos caranguejos (Crustacea, Decapoda, Brachyura) em manguezais impactados da Baía de Guanabara. II- Manguezal do Rio Iguaçu, Duque de Caxias, Rio de Janeiro. In: III Simpósio de Ecossistemas da Costa Brasileira: subsídios a um gerenciamento ambiental. São Paulo, Publicações da ACIESP nº 87-I: 151-156.

VILLAÇA, R.C. 1990. Metodologia de amostragem em costões rochosos: abordagem fitossociológica. In: II Simpósio de Ecossistemas da Costa Sul e sudeste Brasileira: estrutura, função e manejo. São Paulo, Publicação ACIESP $n^{\circ}$ 71-3: 1-13.

WarburG, M.R.; S. GoldenberG \& B. Tudiver. 1987. Osmotic and ionic regulation in two Pachygrapsus crabs, under varying salinities and dehydration. Comp. Biochem. Physiol. 86A (4): 761-765. 
WARMAN, C.G.; D.G. REID \& E. NAYLOR. 1993. Variation in the tidal migratory behaviour and rhythmic light-responsiveness in the shore crab, Carcinus maenas. Jour. Mar. Biol. Ass. U.K. 73: 355-364.

WASS, M.L. 1955. The decapod crustaceans of Alligator Harbor and adjacent inshore areas of Northwestern Florida. Quart. Jour. Florida Acad. Scienc. 18 (3): 129-176.

WILLIAMS, A.B. 1984. Shrimps, lobsters, and crabs of the Atlantic coast of the Eastern United States, maine to Florida. Washington, D.C., Smithsonian Institution, XVIII+550p.

YounG, A.M. 1978. Desiccation tolerances for three hermit crab species Clibanarius vittatus (Bosc), Pagurus pollicaris Say and P. longicarpus Say (Decapoda, Anomura) in the North Inlet Estuary, South Carolina, U.S.A. Estuar. Coast. Mar. Scien. 6: 117-122.

Recebido em 20.VII.1997; aceito em 29.VII.1998. 